\title{
A Reforma Sanitária Brasileira durante os governos Dilma: uma análise da conjuntura
}

\author{
The Brazilian Health Reform during the Dilma governments: an \\ analysis of the conjuncture
}

Camila Ramos Reis', Jairnilson Silva Paim ${ }^{\mathbf{1}}$

DOI: 10.1590/0103-1104202113001

RESUMO A Reforma Sanitária Brasileira (RSB) representa uma reforma social, podendo ser analisada como ideia, proposta, movimento, projeto e processo. São poucas as investigações e estudos examinando o processo da RSB em conjunturas recentes. Este artigo tem como objetivo proceder a uma análise de conjuntura do período correspondente aos governos Dilma Rousseff, considerando os fatos políticos produzidos em saúde, os projetos em disputa e a atuação de sujeitos. Trata-se de um estudo de caso, fundamentado num referencial marxista e utilizando metodologia de análise de conjuntura entre a posse e o impeachment da presidenta, com vistas a identificar fatos produzidos e divulgados na mídia, em publicações e sites. A análise realizada, tendo como referências o projeto da RSB e o desenvolvimento do Sistema Único de Saúde (SUS), indica que o processo da RSB sofreu alteração no período devido à mudança na correlação de forças, tanto no setor quanto na sociedade. Conclui que o retrocesso do processo da RSB pode estar associado ao caráter regressivo das modificações na conjuntura desencadeadas a partir das Jornadas de Junho de 2013.

PALAVRAS-CHAVE Reforma dos serviços de saúde. Políticas de saúde. Sistema Único de Saúde.

\begin{abstract}
The Brazilian Health Reform (RSB) represents a social reform and can be analyzed as an idea, proposal, movement, project and process. There are few investigations and studies examining the RSB process in recent conjunctures. This article aims to carry out a conjuncture analysis in the period corresponding to the Dilma Rousseff governments, considering the political facts produced in health, the disputed projects and the performance of subjects. This is a case study, based on a Marxist framework and using a methodology for analyzing the situation between the president's inauguration and impeachment, with a view to identifying facts produced and disseminated in the media, in publications and websites. as references the RSB project and the development of the Unified Health System (SUS), indicates that the RSB process underwent changes in the period due to changes in the correlation of forces, both in the sector and in society. It concludes that the setback of the RSB process may be associated with the regressive nature of the changes in the situation triggered after the June 2013 Days.
\end{abstract}

KEYWORDS Health care reform. Health policy. Unified Health System.

1 Universidade Federal da Bahia (UFBA), Instituto de Saúde Coletiva (ISC) Salvador (BA), Brasil. camila.ramos@ufba.br 


\section{Introdução}

A Reforma Sanitária Brasileira (RSB) tem sido objeto de investigação, com diferentes perspectivas teóricas. Enquanto fenômeno sócio-histórico, a RSB vem sendo analisada como ideia, proposta, movimento, projeto e processo'.

Diante das diversas transformações políticas, econômicas e sociais que a sociedade brasileira vem enfrentando, com perda de direitos, autoritarismo e priorização das políticas neoliberais, outras análises sobre a RSB se fazem necessárias.

Pesquisas sobre a atuação de governos na área de saúde têm apontado certas continuidades e mudanças em distintas conjunturas. Alguns estudos avaliam aspectos da conjuntura política, não só sinalizando alterações nas agendas em relação a governos, mas apontando impasses, contradições e obstáculos para a garantia do direito à saúde ${ }^{2-4}$. Outros indicam alterações nas agendas em relação a governos anteriores, ressaltando impasses, contradições e obstáculos para a garantia do direito à saúde ${ }^{5,6}$. Existem ainda contribuições sobre as mudanças ocorridas nas políticas de saúde no Brasil em diferentes âmbitos e dificuldades na consolidação de um sistema nacional universal, equânime e igualitário ${ }^{3-5}$. Assim, a crise econômica, os impactos do novo regime fiscal, o golpe de 2016, a austeridade fiscal, a abertura ao capital estrangeiro e a privatização do sistema de saúde brasileiro impõem limites políticos para a consolidação e preservação do Sistema Único de Saúde (SUS), assim como para o avanço do processo da RSB6.

Considerando a RSB como processo, foram identificadas na revisão de literatura poucas publicações resultantes de pesquisas concernentes à análise política em saúde nos governos da presidenta Dilma ${ }^{5,6}$, justificando o desenvolvimento do presente estudo, que busca responder à seguinte pergunta de investigação: como explicar os fatos políticos em saúde, projetos e a ação de sujeitos no processo da RSB entre 2011-2016?
Desse modo, este artigo tem como objetivo proceder a uma análise de conjuntura, considerando os fatos políticos produzidos em saúde, os projetos em disputa e a atuação de sujeitos no período correspondente aos governos Dilma Rousseff.

\section{Metodologia}

Trata-se de um estudo de caso de caráter histórico ${ }^{7}$, por meio de pesquisa documental sobre fatos produzidos na conjuntura correspondente ao período de janeiro de 2011 a maio de 2016. O quadro teórico de referência elaborado para pesquisa baseou-se nos conceitos de conjuntura, bloco histórico, hegemonia, classes sociais, relações de força, situação, estratégia, entre outros ${ }^{8-15}$.

A conjuntura está relacionada às inter-relações das diversas forças (sociais, políticas, econômicas) em uma determinada situação, onde diferentes forças sociais se expressam em oposição (luta de classes) ${ }^{\mathbf{1 6}}$. Desse modo, a estratégia é caracterizada pela forma como as organizações se comportam em relação à superação dos problemas ${ }^{14}$. Os atores sociais adotam táticas e ações empreendidas na conjuntura, que podem ser de resistência, acumulação de forças e conquistas parciais no jogo do poder ${ }^{10}$.

O ‘bloco histórico’ é formado pela infraestrutura (economia) e a superestrutura (ideologia e política), sendo uma expressão das relações sociais de produção $0^{9}$. Caracteriza-se pela relação entre grupos dominantes e dominados, a partir de contradições e conflitos ${ }^{17}$. A sociedade civil abrange um conjunto de organizações responsáveis por difundir a ideologia e construir a hegemonia. Já a sociedade política, equivalente ao Estado restrito, é aquela constituída pelos mecanismos que garantem a manutenção da força pela classe dominante ${ }^{\mathbf{1 3}}$.

Assim, a presente investigação baseou-se na análise de conjuntura, que supõe o exame de um feixe de relações (relações de força) e implica o conhecimento do seu 
desenvolvimento desigual em cada um dos níveis que articuladamente compõem a totalidade social ${ }^{13}$. Portanto, buscou-se investigar os fatos políticos produzidos, a atuação dos sujeitos e a correlação de forças políticas e sociais em certos recortes do tempo.

Ao diferenciar um grupo social de uma classe social, Testa ${ }^{\mathbf{1 4}}$ afirma que um grupo social seria aquele possível de se identificar que realiza o trabalho concreto. A classe social é uma categoria, sendo necessário entendê-la analiticamente para que se possa compreender a realidade. Ambos, grupo e classe, possuem interesses. Assim, para fins de análise da conjuntura, faz-se necessário entender a estrutura de classe no Brasil e como ela foi se organizando e localizando na sociedade.

A metodologia adotada utilizou procedimentos sistematizados na literatura para a análise de conjuntura ${ }^{18-21}$ e como estratégia de produção dos dados foram utilizados documentos e notícias divulgados na mídia (impressa e eletrônica) e em publicações oficiais e de entidades de saúde, tais como: programas de candidatos nas eleições presidenciais de 2010 e 2014, Diário Oficial, sites do Ministério da Saúde, Centro Brasileiro de Estudos de Saúde (Cebes), Associação Brasileira de Saúde Coletiva (Abrasco), Conselho Nacional de Secretários de Saúde (Conass), Conselho Nacional de Saúde (CNS), Conselho Nacional de Secretarias Municipais de Saúde (Conasems), Conselho Federal de Medicina (CFM), Associação Médica Brasileira (AMB), Agência Nacional de Saúde Suplementar (ANS), Observatório de Análise Política em Saúde (OAPS).

O registro de dados decorrente do levantamento de documentos oficiais e matérias da mídia escrita foi armazenado em arquivos impressos e/ou digitalizados. Os dados foram analisados utilizando matrizes em Excel $^{\varpi}$, organizadas da seguinte forma: a) notícias obtidas nos sites das entidades, agências e órgãos governamentais da saúde; b) do site Saúde Legis; c) notícias da mídia impressa e eletrônica; d) levantamento e sistematização dos fatos.
A partir do material empírico, com a identificação dos principais fatos políticos, foi realizada a análise de conjuntura, tendo em conta a RSB e distintos momentos de conformação de projetos, sujeitos, estratégia e táticas da conjuntura antes e depois das Jornadas de Junho de 2013.

\section{Resultados e discussão}

Nesta análise de conjuntura, foi possível destacar, pelo menos, três momentos do processo da RSB durante os governos Dilma.

O primeiro diz respeito ao 'ensaio desenvolvimentista' que corresponde ao seu $1^{\circ}$ governo (até o ano de 2013), ressaltando o 'neodesenvolvimentismo' e os seguintes fatos: a) continuidade das políticas desenvolvidas no governo Lula, a exemplo do PAC e do 'Minha casa, minha vida'; b) implantação da 'Nova Matriz Econômica' (NME); c) implementação de políticas anticíclicas em resposta à crise de 2008 e seus efeitos; d) redução das taxas de juros; e) implantação de políticas racionalizadoras na saúde; f) aprovação da Lei ${ }^{\circ}$ 141/2011; g) Jornadas de Junho de 2013; e, h) PEC do Orçamento Impositivo (PEC ${ }^{\circ}$ 358/2013), com repercussões no SUS.

O segundo momento corresponde ao período ulterior às Jornadas de Junho, incluindo o ano de 2014, com alguns fatos importantes: a) abertura ao capital estrangeiro no setor da saúde; b) PEC $\mathrm{n}^{\circ} 451 / 2014$ propondo planos privados para todos os trabalhadores, exceto empregados domésticos; c) consideração da proposta internacional de Cobertura Universal em Saúde; d) rebaixamento da seguridade social; e) saída do Brasil do 'mapa da fome'; f) agravamento da crise econômica e dificuldades políticas diante do ajuste fiscal, da perda de apoio parlamentar e da Operação Lava Jato.

O terceiro momento superpõe-se ao segundo governo Dilma, onde podem ser ressaltados os seguintes fatos: a) mudança na condução econômica, com nítido atendimento aos 
interesses do mercado e do capital; b) ajuste fiscal com redução das políticas sociais; c) ataques ao SUS e aos direitos sociais; d) golpe jurídico-parlamentar-midiático resultando no impeachment; e, e) aprovação da Emenda Constitucional 95 (EC-95).

\section{Estrutura de classes e 'bloco histórico'}

Neste tópico, busca-se analisar a estrutura de classe no Brasil e como ela foi se expressando na sociedade durante a conjuntura pesquisada.

Enquanto a mídia registrava o crescimento da 'classe média', Chauí ${ }^{22}$ ressaltava que as classes sociais, para além da dimensão econômica, também se caracterizam pelos valores e ideologias, registrando o surgimento da chamada 'nova classe trabalhadora'. Ainda assim, a composição, inserção econômica e social, forma de expressão e consciência criavam dúvidas na sua caracterização, mesmo quando se utilizavam os conceitos de 'subproletariado' ou de 'precariado'.

Essa 'classe média' segue uma ideologia conservadora, influenciada pela economia neoliberal, incorporando formas autoritárias das relações sociais e valorizando a fragmentação socioeconômica e o individualismo competitivo. Dessa forma, a 'nova classe trabalhadora' enfrentava dificuldades para ser absorvida pelas classes dominantes e no imaginário da classe média. Assim, era possível identificar duas manifestações ideológicas: a) teologia da prosperidade (pentecostalismo) e b) 'empreendedorismo' quando o acesso ao 'consumo de massa' reforça a ideia de ascensão social22.

Boito $^{23}$ menciona a existência de duas frações 'burguesas', além das classes populares: o 'grande capital' e o 'conjunto de empresas de pequeno e médio porte'. A primeira se divide em 'grande burguesia interna' (com o objetivo de garantir o crescimento do capitalismo nacional) e a 'fração internacionalizada da burguesia brasileira' (articula-se com o capital financeiro e produtivo internacional). A segunda, formada por empresas de pequeno e médio porte, tem um poder econômico e influência política reduzidos, não dispondo de uma organização e programa político próprio. No início do governo Dilma, foi possível observar disputas entre as burguesias interna e internacionalizada, lembrando que a partir de 2008 a burguesia interna assumiu a hegemonia no bloco do poder.

Essas forças sociais se manifestaram de formas distintas nos três momentos da análise da conjuntura. As políticas implantadas no início do governo (primeiro momento) tiveram relação com o 'ensaio desenvolvimentista', onde a presidenta tentou acelerar o 'lulismo'24. Porém, nessa empreitada, ela se afasta do ex-presidente Lula e desestabiliza as bases do 'lulismo'. Cumpre registrar que no início da gestão foi articulado uma espécie de acordo entre o governo e os 'produtivistas'. Em maio de 2011, esse grupo, composto pela Federação das Indústrias de São Paulo (Fiesp), Central Única dos Trabalhadores (CUT), Força Sindical e os Sindicatos dos Metalúrgicos de São Paulo e do ABC, entregou um documento com diversas propostas visando à melhoria do setor produtivo ${ }^{25}$, que embasou as ações implantadas nos meses seguintes, a exemplo do Plano Brasil Maior. A Confederação Nacional da Indústria, que não participou do acordo feito com o governo no início de 2011, lançou um documento no final de 2012, trazendo propostas para a 'modernização' da Consolidação das Leis do Trabalho' ${ }^{26}$. Esse ato simbolizou o afastamento dos industriais em relação à presidenta. Houve também divergências entre a Fiesp e a CUT ${ }^{27}$.

Outras contradições podem ter dificultado o 'neodesenvolvimentismo'. Na grande burguesia interna, havia divergências entre o capital bancário e o produtivo, a indústria de transformação e o agronegócio, dentre outras 27,28. Havia contradições na classe trabalhadora e nas frações da burguesia, ou seja, na infraestrutura econômica da estrutura social. No movimento sindical e popular, identificava-se a criação de centrais sindicais que faziam oposição ao governo (Conlutas e a Intersindical) e 
no Movimento dos Trabalhadores Rurais Sem Terra havia correntes que apoiavam o governo e outras que pretendiam romper com o mesmo.

Contudo, essas contradições não afetaram a unidade geral da frente 'neodesenvolvimentista'. Na realidade, o que conseguiu comprometer e polarizar a política nacional foi o campo neoliberal ortodoxo ${ }^{29}$. Assim, a estrutura de classes da sociedade brasileira se expressava, política e dinamicamente, nas lutas da superestrutura político-ideológica do 'bloco histórico' durante a conjuntura investigada. A situação desse 'bloco histórico' tornava-se ainda mais complexa devido às relações internacionais que influenciavam a política interna. Os argumentos de que o setor industrial tem conflito com o capital bancário nacional ${ }^{30(179)}$ e de que as empresas de capital nacional possuem interesses que as opõem às de capital internacional ${ }^{27(58)}$ reforçam as contradições rentistas e produtivistas. Na realidade, o programa firmado em 2011 se encaixava tanto na grande burguesia interna ${ }^{30}$, quanto no setor produtivo da burguesia ${ }^{27}$.

Em relação à política macroeconômica, Dilma apostou em continuidades (e algumas mudanças) em relação ao governo Lula, ao manter os programas sociais e valorizar o salário mínimo ${ }^{31}$. Ao iniciar o 'ensaio desenvolvimentista' e pactuar com a 'coalizão produtivista', enfrentou pressão do capital financeiro, articulado com a classe média. Dilma queria controlar a entrada do capital estrangeiro no país e promover uma valorização do produto nacional. Para isso ela interveio nas taxas de juros e em outros pontos da economia ${ }^{27}$.

Para deslegitimar a presidenta, as classes dominantes começaram a disseminar a ideia de que ela estava efetuando uma política intervencionista, que essa ação inviabilizava os interesses do mercado e não assegurava a confiança dos investidores. A grande mídia apoiou essa posição e, em abril de 2013, o Banco Central aumentou a taxa Selic. Esse fato demonstra a disputa pelo controle da política econômica. De um lado o governo, que ao tentar se articular e valorizar a política para o mercado interno foi combatido. Do outro, o capital financeiro, articulado com o capital estrangeiro que era beneficiado pelas políticas neoliberais e obteve o apoio da burguesia, da classe média, de alguns segmentos da classe trabalhadora, além dos seus porta-vozes na grande mídia.

O governo apostou num 'bloco histórico' com a 'coalizão produtivista', que naquele momento representava o capital industrial e a classe trabalhadora. Porém, esse bloco foi rompido ao sofrer influência do capital financeiro e da classe média, estimulados pelo capital estrangeiro, assim como por mudanças na superestrutura político-ideológica pela ação da grande mídia e de outras forças sociais. Então, o capital industrial se afastou da presidenta e articulou-se com a 'coalizão rentista', que era aliada ao Partido da Social Democracia Brasileira (PSDB).

Esse afastamento do capital industrial resultou na criação da frente única burguesa, composta pela burguesia, classe média e setores da classe trabalhadora, em oposição ao 'neodesenvolvimentismo' de Dilma. Alguns pontos podem ter sido estímulos para esse deslocamento, tais como: a) a financeirização do capitalismo teria levado à mistura entre capital da indústria e das finanças; b) afastamento do capital e do trabalho, a partir do 'pleno emprego', melhoria dos salários e fortalecimento dos sindicatos; c) mobilização da 'coalizão rentista' em torno da ideologia anti-intervencionista (críticas de incompetência, autoritarismo e corrupção); d) correlação de força internacional; e) abertura de diversas frentes de luta simultaneamente, dedicando-se a micro gerenciar projetos ${ }^{27}$. Em 2013, houve diversas greves a partir das modificações das pautas sindicalistas e dos ganhos salariais. O acesso à universidade (políticas de cotas, Programa Universidade para Todos - ProUni, Programa de Apoio a Planos de Reestruturação e Expansão das Universidades Federais Reuni e Fundo de Financiamento Estudantil - Fies) representou não só a contemplação de políticas democratizantes, como também surgiu uma nova demanda: a de ser absorvido 
pelo mercado de trabalho. Porém, esse grupo não encontrou o que julgava ter garantido, refletindo numa insatisfação e retirada do apoio ao 'neodesenvolvimentismo' 29 . Esse ciclo de greves e as instabilidades das classes subalternas representam os limites e ambiguidades do projeto 'lulista'32.

Ao 'cutucar onças com varas curtas', associando aos efeitos das Jornadas de Junho de 2013, a explosão da Lava Jato, a intensa dedicação da mídia em relação ao combate à corrupção e à oposição do parlamento, Dilma nem fez uma aliança interclassista, nem conseguiu um apoio efetivo e mobilização dos trabalhadores. Desta forma, a presidenta enfrentou intensa oposição nesse segundo momento da conjuntura analisada. As eleições presidenciais de 2014 expressaram, politicamente, distintas polarizações, com uma disputa acirrada no segundo turno e um questionamento dos resultados por parte do candidato derrotado.

Após as eleições, correspondendo ao terceiro momento dessa análise, a presidenta ainda tentou contornar a situação, atendendo interesses burgueses. Destaca-se a substituição de ministros da Fazenda (Mantega por Levy) e a adoção de um ajuste fiscal. No segundo governo, Dilma colocou em prática o projeto proposto pelo seu adversário político. Esta ação não impediu que o capital financeiro, junto dos empresários, articulassem, desde então, para o golpe do capital6. Consequentemente, tais ações desestabilizaram sua base social, assim como o 'lulismo', já que seus eleitores não viram de forma positiva sua atuação, realizando um programa que combatera no processo eleitoral.

Diante de tantos problemas, da perda de apoio político e com a crise orgânica fruto das mudanças na estrutura social, estimulada pela luta de classe, a presidenta Dilma provocou uma crise no 'lulismo', mesmo enquanto 'reformismo fraco', deixando espaços para a abertura do pedido de impeachment ${ }^{27,32}$ e para a consumação do Golpe de 2016.

Finalmente, um aspecto considerado fundamental para a análise de conjuntura diz respeito aos papéis da mídia, dos intelectuais e da religião, assim como das ideologias presentes no 'bloco histórico' (meritocracia, nacionalismo, empreendedorismo, machismo etc.). Assim, o exame dessa instância superestrutural passa pela investigação da mídia e da religião como dimensões da cultura ${ }^{33}$.

\section{Sujeitos e projetos em disputa}

A partir do neoliberalismo no Brasil, houve uma nova configuração do capital financeiro internacional fazendo parte do bloco dominante. Compõem o bloco do poder os grandes grupos econômicos e os capitais especializados na acumulação (agronegócio, indústria, comércio ou serviço). Apesar de a maioria dos grupos econômicos não estar ligada, organicamente, ao capital financeiro, ambos se beneficiam da especulação e do financiamento da dívida pública, ganhando também com as elevadas taxas de juros, tendo a classe média alta como uma grande aliada desse projeto e da política neoliberal ${ }^{34}$.

A partir da crise mundial de 2008, os países dominantes responderam através da estatização das dívidas para salvar os bancos, com ênfase em políticas neoliberais e o reforço na financeirização da economia, emitindo críticas em relação às políticas universais e ao Welfare State ${ }^{6(12)}$. Com o agravamento da crise em 2011 e os desgastes no âmbito macroeconômico, houve um retorno da disputa entre as frações do capital, intensificada pelo Estado e pela mídia.

Assim, diversos projetos estavam em disputa na sociedade, dentre eles: a) liberalismo social ou social-democracia ('neodesenvolvimentismo'), tentativa do primeiro governo Dilma; b) neoliberalismo, com a proposta da 'nova agenda social' e o documento elaborado pelo Banco Mundial ${ }^{35}$; e, c) socialista ou democrático-popular, ligado aos grupos de esquerda.

Após as Jornadas de Junho (segundo momento) e, especialmente, a partir das eleições de 2014 (terceiro momento), dois projetos políticos disputavam: 1) 'Uma ponte para o futuro' (Plano Temer) ${ }^{36}$, com a proposta do 
novo regime fiscal e reformas com o objetivo de reduzir os gastos sociais, favorecendo o setor privado e 2) 'Por um Brasil Justo e Democrático'37, que propunha ações de curto e longo prazo, criticando as medidas de ajuste fiscal, recomendando a retomada do crescimento, preservando o emprego e revertendo a recessão econômica, entre outros ${ }^{\mathbf{3 8}}$.

Havia diversas disputas entre os sujeitos. As mudanças que ocorreram na sociedade, especialmente após as Jornadas de Junho, contribuíram para as disputas entre a classe média, as igrejas, especialmente as pentecostais, as Centrais Sindicais, os partidos, os movimentos sociais e o capital.

A articulação entre estrutura e conjuntura indica, portanto, as relações que os fatos estabelecem com a história, mediante as relações sociais, econômicas e políticas. Entre os enfrentamentos existentes na sociedade, além dos projetos em disputas, destacaram-se a atuação da 'coalizão produtivista', ao articular com o governo a pactuação de 2011. Já que essa coalizão foi capaz de induzir uma agenda no Estado, considera-se que tenha desempenhado o papel de ator social ${ }^{14}$. Por outro lado, a 'coalizão rentista', enquanto ator social, se colocou numa posição dominante, atuando como uma força de confronto e chegando a impulsionar uma mudança de postura da presidenta após as Jornadas de Junho (segundo e terceiro momentos).

\section{A saúde na conjuntura}

Era possível observar, de início, dois projetos, já referidos, em disputa no Brasil, que se refletiam na saúde. O primeiro pretendia intensificar as reformas iniciadas no período de FHC, a chamada 'nova agenda social'39. O segundo seria o 'neodesenvolvimentismo' com propostas para o setor da saúde ${ }^{40}$.

Ao se considerar o projeto da RSB como referência para a análise da conjuntura, é possível identificar duas concepções de SUS: o 'SUS para pobre' e o 'SUS da RSB'. Além disso, existiam pelo menos três projetos em disputa na saúde: o mercantilista ou privatista, o revisionista ou racionalizador e o democrático ou da RSB41.

Ao lado do projeto mercantilista, o projeto racionalizador ganhou força no primeiro governo da presidenta Dilma, destacando-se a atenção básica e a atuação focalizada dos Agentes Comunitários de Saúde (ACS). A ênfase em medidas racionalizadoras parecia reforçar o projeto revisionista. Esta tendência se estendeu durante as negociações da regulamentação da Emenda Constitucional 29 (EC-29), efetivada com a aprovação da Lei Complementar $n^{\circ} 141 / 2012$. O projeto democrático (RSB) não foi priorizado, apenas defendido pelas entidades e instituições vinculadas ao movimento sanitário, a exemplo do Projeto de Lei de Iniciativa Popular (Plip) $n^{0} 321 / 2013$ - Saúde+10.

A aprovação da lei que permite a abertura ao capital estrangeiro nas ações e cuidados à saúde indicava uma vitória da coalizão de interesses de hospitais privados, empresas farmacêuticas e operadoras de planos de saúde ${ }^{\mathbf{4 2}}$. Demonstrava a atuação do Legislativo em defender os interesses do mercado e na agilidade em desmontar os direitos sociais ${ }^{\mathbf{3}}$.

Apesar de sancionada a LC 141, a rejeição do projeto de lei 'Saúde +10' e a aprovação da PEC 358 (orçamento impositivo) representaram grande retrocesso. E, com o crescimento dos planos privados de saúde, incorporação de novas tecnologias de alto custo e financeirização do setor, verifica-se uma expansão da mercantilização, persistindo o subfinanciamento, a sub-regulação e a privatização da saúde. Houve uma redução na participação da União na despesa pública, crescendo a participação dos estados e municípios, principalmente com a proposta de prolongamento da Desvinculação das Receitas das União (DRU), acrescida da Desvinculação das Receitas do Estados (DRE) e Desvinculação de Receitas dos Municípios (DRM).

Enfim, durante o período estudado, foi possível identificar vários ataques ao SUS, especialmente, a partir de $2014^{6,44}$. O Executivo e 
o Legislativo rejeitaram a proposta de $10 \%$ das receitas brutas da União para a saúde, ignorando o movimento Saúde+10, comprometeram a sustentabilidade econômica do SUS e permitiram a abertura da saúde ao capital estrangeiro ${ }^{\mathbf{4 2}}$. O Judiciário reconheceu a constitucionalidade das Organizações Sociais de Saúde (OSS) no Supremo Tribunal Federal depois de 17 anos de protelação, abrindo as portas para as Parcerias Público-Privadas (PPPs), terceirizações, Organizações da Sociedade Civil de Interesse Públicos (Oscips) etc ${ }^{45}$.

Essas derrotas foram impostas por sujeitos e atores sociais vinculados ao projeto mercantilista, especialmente pelas operadoras de planos de saúde que financiaram as campanhas eleitorais de 2010 e 2014, ilustrando a influência do capital financeiro sobre as políticas públicas no Brasil.

\section{Estratégias, forças políticas, bases sociais e práxis da RSB}

Entidades como o Cebes, Abrasco, Associação Brasileira de Economia da Saúde (Abres), Rede Unida, Conferência Nacional dos Bispos do Brasil (CNBB), movimentos populares, pesquisadores, intelectuais e a Associação Nacional do Ministério Público de Defesa da Saúde, durante todo o período estudado, defenderam a RSB e o SUS. No âmbito da gestão, o Conass, Conasems e a Frente Parlamentar da Saúde também se articularam em prol da defesa do SUS. A atuação das entidades ligadas ao movimento sanitário que lutaram contra a perda de diversos direitos enfrentou a mudança na correlação de forças político-ideológicas desfavoráveis ao avanço da RSB, dos direitos dos trabalhadores e da população. Apesar das perdas de direitos e retrocesso, a RSB foi capaz de se articular e mobilizar aqueles que apostavam em um país com menos desigualdade.

Portanto, ao analisar os atores sociais, pode-se considerar a existência de sujeitos organicamente vinculados ao capital e alguns que foram cooptados defendendo o projeto mercantilista que se apoia nos aparelhos hegemônicos da mídia, entidades de saúde e universidades. O projeto racionalizador conta com os sujeitos que fazem parte do governo (gestores e funcionários do governo). Por fim, o projeto da RSB direciona-se a partir do pensamento e práxis do movimento sanitário, tem o Cebes e outras entidades que apoiam o projeto estimulando a constituição de novos sujeitos sociais ${ }^{46}$

Apesar do Ministério da Saúde ter sido ocupado por sanitaristas ligados ao movimento sanitário, houve subordinação de dirigentes na correlação de forças internas ao governo, sobretudo em relação à área econômica, com comportamentos que sugerem o fenômeno do 'transformismo'.

A situação se agravou no segundo governo, quando o então PMDB ocupou o Ministério da Saúde numa negociação político-partidária. A partir daquele momento, o projeto mercantilista foi fortalecido e o SUS sofreu vários ataques.

Ao analisar os fatos produzidos na conjuntura, constata-se que o desenvolvimento da RSB e do SUS são condicionados e determinados pela correlação de forças e pelas suas bases de sustentação política ${ }^{47}$. Apesar do apoio dos movimentos populares, trabalhadores da saúde, técnicos, pesquisadores, Cebes, Abrasco, Rede Unida, Abres, Frente Parlamentar, Conass, Conasems e, recentemente, Associação Nacional do Ministério Público de Defesa da Saúde (Ampasa), Frente Povo Sem Medo, Frente Brasil Popular, Médicos pela Democracia, Médicos Populares e outros movimentos que defendem o lema 'Nenhum direito à menos', essas bases políticas não foram suficientes para evitar os retrocessos. A lista de opositores ainda é grande e poderosa, dentre eles: partidos do centro e direita; empresários da saúde; corporações profissionais; capital financeiro (planos de saúde através da Federação Brasileira de Bancos); Associação Nacional de Hospitais Privados; Banco Mundial; capital industrial (medicamentos, equipamentos, vacinas e atuação do Ministério da Ciência, Tecnologia e Inovações), capital produtivo e Ministério da Saúde. 


\section{Considerações finais}

Ao apontar os fatos políticos, projetos em disputa, sujeitos e a atuação de atores na conjuntura, foi possível confirmar que o 'processo' da RSB sofreu alteração no período estudado devido à mudança na correlação de forças, tanto no setor quanto na sociedade. Houve nos governos Dilma uma opção pelo 'lulismo parcial' e o 'ensaio neodesenvolvimentista'. Essa decisão comprometeu as políticas universais, com redução do financiamento da seguridade social e certa continuidade da política macroeconômica desenvolvida nos governos FHC e Lula, a exemplo do tripé macroeconômico. No entanto, outras análises de conjuntura devem ser consideradas no sentido de decifrar esta história recente do Brasil. Nessa perspectiva, o estudo de Zacarias ${ }^{48}$ fornece indicações relevantes, não só para interpretar os impasses dos governos Dilma, mas, sobretudo, para compreender o fortalecimento das forças da direita no país e no chamado 'bolsonarismo'.

No que diz respeito ao movimento sanitário, foi possível descrever a intensa atuação e resistência das entidades ligadas à RSB no combate aos retrocessos dos direitos sociais e da saúde, com a defesa da democracia, destacando-se a reiteração do lema do Cebes, 'Saúde é democracia. Democracia é Saúde'. Contudo, foram impostos alguns limites para o processo da RSB e o desenvolvimento do SUS que estão ligados às questões estruturais, à composição das classes sociais e à correlação de forças políticas e ideológicas que disputaram projetos na sociedade e na saúde.

Assim, o processo da RSB foi alterado na conjuntura analisada. Com as mudanças estruturais sublinhadas no decorrer da investigação, especialmente, no que diz respeito às classes sociais e ideologias, associadas às derrotas do 'lulismo' e do 'neodesenvolvimentismo', o projeto 'neoliberal' ganhou força.

Na saúde, a falta de sustentação política e ausência de bases sólidas no Legislativo, aprofundaram ainda mais esses limites impostos à RSB. Apesar do apoio das entidades de saúde, de parte dos gestores e de políticos, os oponentes da RSB e do SUS demonstraram mais poder nessa conjuntura, principalmente vinculado ao capital. Desta forma, pode-se enfatizar que houve uma correlação de forças desfavorável ao processo da RSB, com uma hegemonia da burguesia financeira e industrial, especialmente sob influência do capital estrangeiro, viabilizada pela entrada desse capital no setor saúde do país.

Assim, o retrocesso do processo da RSB verificado na conjuntura pode estar associado ao caráter regressivo das modificações desencadeadas a partir das Jornadas de Junho, que parecem culminar no fortalecimento de grupos conservadores, na direita, no ultraliberalismo econômico, no autoritarismo e no neofascismo.

Em conclusão, este estudo sugere que o processo da RSB persiste, sobretudo pelo ativismo do movimento sanitário, apesar dos constrangimentos e retrocessos apontados pela análise da conjuntura. Desse modo, argumenta-se a necessidade de constituição de novos sujeitos que possam se articular com instituições, movimentos e entidades a fim de garantir uma sustentabilidade política e social para o projeto da RSB.

\section{Colaboradores}

Reis CR (0000-0001-5646-4355)* e Paim JS (0000-0003-0783-262X)*, contribuíram igualmente para a elaboração do manuscrito. 


\section{Referências}

1. Paim JS. Reforma Sanitária Brasileira: Contribuição para a compreensão e crítica. Salvador: Edufba; 2008.

2. Paim JS, Travassos C, Almeida C, et al. O sistema de saúde brasileiro: história, avanços e desafios. Londres: The Lancet. 2011; (11): 60054-8.

3. Castro MC, Massuda A, Almeida G, et al. Brazil's unified health system: the first 30 years and prospects for the futures. Londres: The Lancet. 2019 [acesso em 2020 jun 20]; 394(10195):345-356. Disponível em: https://cutt.ly/Hg7lncZ.

4. Santos L. SUS-30 anos: um balanço incômodo? Ciênc. Saúde Colet. Rio de Janeiro. 2018; 23(6):2043-2050.

5. Machado CV, Lima LD, Baptista TWF. Políticas de saúde no Brasil em tempos contraditórios: caminhos e tropeços na construção de um sistema universal. Cad. Saúde Pública. 2017; 33(2):143-161.

6. Teixeira CFS, Paim JS. A crise mundial de 2008 e o golpe do capital na política de saúde no Brasil. Saúde debate. 2018; 42(2):11-21.

7. Yin RK. Estudo de caso: planejamento e métodos. 3. ed. Porto Alegre: Bookman; 2005.

8. Gramsci A. Maquiavel, a Política e o Estado Moderno. Rio de Janeiro: Civilização Brasileira; 1976.

9. Gramsci A. Cadernos do Cárcere. Volume 1: Introdução ao estudo da filosofia. A filosofia de Benedetto Croce. Rio de Janeiro: Civilização Brasileira; 1999.

10. Gramsci A. Cadernos do Cárcere. Volume 3: Maquiavel - Notas sobre o Estado e a política. Rio de Janeiro: Civilização Brasileira; 2000. p. 19-46.

11. Gramsci A. Cadernos do Cárcere. Volume 3: Maquiavel - Notas sobre o Estado e a política. Rio de Janeiro: Civilização Brasileira. 2000; p. 45-46.

12. Gramsci A. Cadernos do Cárcere. Volume 5. Rio de Janeiro: Civilização Brasileira; 2002.
13. Portantiero JC. Gramsci Y. El análisis de coyuntura (algumas notas). In: Portantiero JC. Los usos de Gramsci. México: Folio; 1983.

14. Testa M. Pensamento estratégico e lógica de programação. O caso da saúde. São Paulo: Hucitec; 1995.

15. Liguori G, Voza P. Dicionário Gramsciano (1926-1937). São Paulo: Boitempo; 2017.

16. Harnecker M. Os conceitos elementais do materialismo histórico. Rio de Janeiro: Graal; 1973.

17. Portelli H. Gramsci e o bloco histórico. Rio de Janeiro: Paz e Terra; 1977.

18. Silva LEP. Metodologia de Análise de Conjuntura. São Leopoldo: Estudos Teológicos; 1988.

19. Alves JED. Análise de conjuntura: teoria e método. Aparte - Inclusão Social em Debate. Mimeo: Rio de Janeiro; 2008.

20. Souza HJ. Como se faz análise de conjuntura. Petrópolis: Vozes; 2014.

21. Virgens JHA, Teixeira CF. Revisão da produção científica sobre análise de conjuntura: contribuição à análise política em saúde. Saúde debate. 2018; 42(2):377-393.

22. Chauí M. A nova classe trabalhadora e a ascensão do conservadorismo. In: Jinkings I, Doria K, Cleto M. Por que gritamos golpe?: para entender o impeachment e a crise política no Brasil. São Paulo: Boitempo; 2016. p. 15-22.

23. Boito AJR. Uma crise no caminho do neodesenvolvimentismo. Hist. Luta de classes. 2016; 12(22):83-95.

24. Singer A. O lulismo em crise: um quebra-cabeça do período Dilma (2011-2016). São Paulo: Companhia das Letras; 2018.

25. Skaf P, Henrique A, Silva PP. Um acordo pela indústria brasileira. Folha de São Paulo. 2011 maio 26. 
[acesso em 2020 ago 11]. Disponível em: https://cutt. ly/Bg7loDk.

26. Confederação Nacional da Indústria. 101 propostas para modernização trabalhista. Brasília, DF. CNI; 2012.

27. Singer A. Cutucando Onças com Varas Curtas: O ensaio desenvolvimentista no primeiro mandato de Dilma Rousseff (2011-2014). São Paulo: Novos Estudos; 2015.

28. Boito AJR. A crise política do neodesenvolvimentismo e a instabilidade da democracia. São Paulo: Crítica Marxista; 2016.

29. Boito AJR. Os atores e o enredo da crise política. In: Jinkings I, Doria K, Cleto M. Por que gritamos golpe?: para entender o impeachment e a crise política no Brasil. São Paulo: Boitempo; 2016. p. 23-29.

30. Boito AJR. O lulismo é um tipo de bonapartismo? Uma crítica às teses de André Singer. São Paulo: Crítica Marxista; 2013. p. 179.

31. Dweck E, Teixeira RA. A política fiscal do governo Dilma e a crise econômica. Campinas: Instituto de Economia; 2017.

32. Braga R. O fim do lulismo. In: Jinkings I, Doria K, Cleto M. Por que gritamos golpe?: para entender o impeachment e a crise política no Brasil. São Paulo: Boitempo; 2016, p. 55-60.

33. Almeida R. Deus acima de todos. In: Democracia em risco?: 22 ensaios sobre o Brasil hoje. São Paulo: Companhia das Letras; 2019. p. 35-51.

34. Filgueiras L. O neoliberalismo no Brasil: estrutura, dinâmica e ajuste do modelo econômico. In: Basualdo EM, Arceo E. Neoliberalismo y sectores dominantes. Tendencias globales y experiencias nacionales. Buenos Aires: Consejo Latinoamericano de Ciencias Sociales; 2006. p. 179-206.
35. Associação Nacional de Hospitais Privados. Livro Branco: Brasil Saúde 2015. A sustentabilidade do Sistema de Saúde brasileiro. Rio de Janeiro: ANAHP; 2015. [acesso em 2018 jan 22]. Disponível em: https:// cutt.ly/Tg7kVXP.

36. Fundação Ulysses Guimarães. Uma ponte para o futuro. 2015. [acesso em 2020 nov 16]. Disponível em: https://cutt.ly/dg7k9BC.

37. Fundação Perseu Abramo; Brasil Debate; Centro Internacional Celso Furtado de Políticas Para o Desenvolvimento, et al. Por um Brasil Justo e Democrático. [Brasília, DF] 2015. [acesso em 2020 nov 16]. Disponível em: https://cutt.ly/rg7k611.

38. Observatório Análise Política em Saúde. Ponte para um país justo e democrático?: Projetos para tirar Brasil da crise disputam agenda econômica em 2016. Salvador: OAPS; 2016. [acesso em 2020 jul 16]. Disponível em: https://bityli.com/TWslm.

39. Bacha EL, Schwartzman S. Brasil: a nova agenda social. Rio de Janeiro: LTC; 2011.

40. Fundação Oswaldo Cruz. A saúde no Brasil em 2030: diretrizes para a prospecção estratégica do sistema de saúde brasileiro. Rio de Janeiro: Fiocruz; 2012.

41. Paim JS. Reforma Sanitária Brasileira: avanços, limites e perspectivas. In: Matta GC, Lima JCF. Estado, Sociedade e Formação Profissional em Saúde: contradições e desafios em 20 anos de SUS. 20. ed. Rio de Janeiro: Fiocruz; 2008.

42. Scheffer M. O capital estrangeiro e a privatização do sistema de saúde brasileiro. Cad. Saúde Pública. 2015; 31(4):663-666.

43. Costa AM, Pêgo RA, Saddi FC, et al. Saúde no poder legislativo: objeto, investigação e tendências. In: Teixeira CF. Observatório de Análise Política em Saúde: abordagens, objetos e investigações. Salvador: Edufba; 2016. 
44. Reis CR, Paim JS. A saúde nos períodos dos governos Dilma Rousseff (2011- 2016). Divulg. saúde debate. 2018. p. 101-114.

45. Marques T, Mendes A. Uma decisão favorável às OSS: impasses à construção do SUS. Domingueira da Saúde. Campinas. 2015.

46. Paim JS. Reforma Sanitária Brasileira: expressão ou reprodução da revolução passiva? In: Fleury $\mathrm{S}$. Teoria da Reforma Sanitária: diálogos críticos. Rio de Janeiro: Fiocruz; 2018; (58):85-114.

47. Magno LD, Paim JS. Dos clamores das ruas aos rumores do Congresso: uma análise da conjuntura recen- te da saúde no Brasil. RECIIS (Online). 2015 [acesso em 2020 jul 16]; 9(4):1-14. Disponível em: https:// www.reciis.icict.fiocruz.br/index.php/reciis/article/ view/1043/1987.

48. Zacarias CSJ. Decifra-me ou devoro-te: as Jornadas de Junho, o Golpe de 2016 e a ascensão da extrema-direita no Brasil. Campos do Paricarana: Boa Vista; 2020.

Recebido em 03/12/2020 Aprovado em 31/05/2021

Conflito de interesses: inexistente

Suporte financeiro: não houve 